cient time has elapsed to demonstrate the futility of restoring binocular fixation by atropia, glasses, prism and stereopticon exercises and other measures.

My conclusions, scattered here and there through this somewhat rambling paper may be tersely stated as follows:

1. Amblyopia is congenital and not acquired; is not improved by tenotomy when high or of long duration; is always present in monocular squint; is not a factor in alternating squint; can be replaced by full acuity of vision after the hitherto good eye has been rendered by accident or disease inferior to the squinting eye.

2. In monocular constant squint the cornea of the squinting eye is turned upward as well as inward.

3. In concomitant or alternating squint, the nonfixing eye is turned upward as well as inward, and with transference of fixation there will be a transference of both the upward and the inward deviation.

4. Donders' theory, extended to include all the muscles supplied by the third nerve, and not the interni alone, is a sufficiently satisfactory explanation of the upward deviation.

5. Atropia and full correction are, in many cases, curative agents.

6. All operations should be done under cocain anesthesia.

7. In monocular squint, vertical equilibrium must be restored by tenotomy, while in alternating; division of the interni is sufficient.

\section{THE MENTAL CONDITION OF ARTHUR DUESTROW.}

A REPORT SUBMITTED TO HIS ATTORNEYS. BY CHARLES GILBERT CHADDOCK, M.D.

Professor of Diseases of the Nerrous System. Marion-sims College of Medicine: Memier of the American Medico Psychological Associa-

tion; formerly Associate Medical Superintendent Northern Michigan Asylum for the Insane: Neurologis to the Rebekah HosDetroit Academy of Medicine, etc.

At the instance of Hon. Charles P. Johnson, his attorney, I examined Arthur Duestrow, with a view to determine whether he was sane or insane. The circumstances to consider were that the client stood indicted for the brutal and motiveless murder of his wife and child; that he had been in confinement, in jail for several months; that he had manifested symptoms indicative of an abnormal mental state; and that the plea of insanity was the only possible preventive of punishment for his atrocious crime. These circumstances made it obligatory upon me to examine him with special reference to the possibility of his feigning insanity as a means of escaping the legal penalty that threatened him.

I visited the prisoner several times in the jail at the Four Courts in St. Louis. He received me kindly and was on all occasions when I was with him polite in manner and remarkably communicative. He always expressed himself with freedom and with every out. ward sign of sincerity. He willingly submitted to my physical explorations, and gave me every opportunity to satisfy myself.

Physical Examination.-He was 26 years of age, and his appearance accorded with his years. He was in a fair state of bodily nutrition, though he weighed several pounds less than hedid at the beginning of his incarceration. Height, nearly six feet. His color was good, and his circulation perfect. The heart was found to be normal; pulse rate, normal. There were no signs of pulmonary disease of any kind. His appetite was excellent and there was no evidence of gastro-intestinal disturbance. There were no symptoms to indicate a diseased condition of the kidneys. His general physical development was good, the muscles were quite firm and fairly developed, considering his past confinement; the skin presented no anomalies. Inspection revealed no marked physical sign of degeneracy. His head was slightly above the average size, and presented no asymmetry. The ears were well formed and the jaws did not deviate markedly from average standards in form.

Nervous System.-There was no indication of paralysis, paresis or incoördination; no tremor. Cutaneous sensibility was normal. The knee jerks were present and equal; the pupils reacted normally to light and accommodation, and were of equal and normal size. Articulation was perfect-distinct, unhesitating; no fibrillary twịtching of tongue or lips. Sight and hearing were perfect, and there was nothing to indicate anomalies of any of the special senses. No complaint of pain of any kind was made, nor of vertigo. There were no scars indicative of epilepsy.

From these findings I assert that Arthur Duestrow was not suffering with any functional or organic disease of the peripheral nervous system or spinal cord; that there was no organic cerebral disease in his case; at least that the presence of such anomalies in him were not discoverable by any means known to science. Thus the only remaining possibility of disease was that of functional cerebral disturbance.

Cerebral Functions.-Emotional state or feelings: There was no sign of depression of feeling-an absence of all the outward expressions of a feeling of sadness or melancholy; the emotions changed with the change of thought, showing no sign of affective inhibition. In striking contrast with such a possibility, his mood, or state of feeling was, on the whole, one of mild expansiveness, expressed in an unmistakable show of satisfaction with self and a manner indicative of a sense of superiority to others.

This emotional state was one that could have no rational root in his circumstances. He was in confinement, deprived of all the amenities of life, associated with the lowest class of men and awaiting trial for his life. Instead of remorse, sorrow, anxiety, fear and depression, his manner, facial expression and conversation revealed a state of mental feeling in striking contrast with these. Had he been an innocent man he would normally have had great cause for fear, since in the newspapers which he received daily he read of the intense popular prejudice against him; as a malingerer, he would necessarily have recognized the small chance of escape he had, even though he simulated insanity to perfection. All these circumstances tending to bring him to some expression of doubts, fear or anxiety for his future, were absolutely without their normal effect on him. On the other hand, the absence of these natural feelings was not occasioned by indifference of his future. The ideas he expressed were in complete accord with his general mood; he was hopeful, ambitious, proud and self-assertive, and the ground for all these was evident in the thoughts he freely expressed, which, at the same time accounted for the apparent absence of remorse and regret. His feeling of satisfaction was so marked and so predominant as to perfectly withstand the presentation and emphasis of facts which would dispel it in any normal person; pervading 
consciousness so exclusively as to overcome any tendency to irritation and anger that would naturally flow from strenuous contradiction and opposition to his views. If this remarkable state of feeling was assumed for the purpose of deception, it was done with a perfection and unchanging persistency that absolutely defied its differentiation from a genuine emotional state.

Aside from this state of mild emotional expansiveness, there was no exaltation of feeling in any way resembling the emotional state, characteristic of mania and maniacal states. Therefore, I pronounce the prisoner free from mania and melancholia, and from any disposition to feign either of these.

To form a judgment of his intellect, conversation was used to test his powers of perception, attention, memory, imagination, reasoning and judgment. $\mathrm{His}$ perceptions were lively and more or less accurate; he had fair power of attention, his thought was quite clear, his reasouing logical, and he displayed remarkable activity of imagination-all with reference to the premises which formed the material of his mental operations. He entertained a great variety of ideas of intricate construction and complicated association. These facts were sufficient to demonstrate that the prisoner was not afflicted with any form of mental weakness or confusional insanity, and that he made no effort to simulate such a disease. The forms of insanity incident to the originally normal brain having thus been excluded, the inquiry became reduced to the existence of the real or feigned existence of some degenerate form of mental disease. Of these forms, the foregoing considerations, taken with other evidences-which need not be enumerated-have already excluded all but one; namely, depressive reasoning insanity, periodical and circular insanity, and the mental diseases from the neuroses, epilepsy, hysteria, etc. Thus by exclusion it was certain that he was sane, or had or was feigning the only remaining form of degenerate insanity - paranoia.

Paranoia is the name of a chronic progressive mental disease, usually manifested in systematized delusions that are of primary origin; that is, delusions that do not arise out of preceding mental depression or exaltation. Commonly this disease is a result of conditions inherent in the brain organization of the individual which determine the form of the disease. Study of cases of paranoia showe that there is always a history of mental symptoms which antedate the development of the perfected delusions, and often other symptoms of a vicious constitutional state of the nervous system in general; and to these are added in many cases the existence of nervous and mental diseases in ancestry that have been influential through heredity. However, paranoia may arise in persons whose heredity is in nowise at fault, and in this case it is usual to find that some decidedly injurious influence has affected the individual early in life in such a way as to lastingly and inherently harm the nervous constitution. Since the constitutional defect which underlies paranoia is imperfection in generation and development, paranoia, with other mental diseases of like origin, is called degenerate. The degeneracy at the bottom of paranoia varies in degree, and we observe corresponding variations in the mental symptoms. Thus the deeper the degeneracy, the earlier the mental disease appears, and the more sure and rapid is the progress to a condition of permanent mental weakness.
The delusions of paranoia all concern the person directly. They are of two kinds: Delusions of persecution and delusions of grandeur. Again, the earlier in life paranoia appears, the greater the chance that the delusions will be of a grand character; hence primary delusions of grandeur indicate deep degeneracy and presage early development of permanent dementia. Arising late in life, the delusions of paranoia are almost certain to be of a persecutory nature, and their character may remain unchanged through out life. Where primary delusions of persecution arise early in life and are on a deeply degenerate foundation, they are apt to change in character, and this change affords a trustworthy indication of the further course of the malady. This change of delusions of persecution is called the transformation. This consists of a change of primary delusions of persecution to delusions of personal aggrandizement. The transformation, whenever it occurs, is a sign that dementia will ultimately come on, and the earlier it takes place, the more rapid the progress to mental weakness will probably be. When the transformation has taken place, there is not necessarily an entire absence of the former persecutory ideas; rather they are overshadowed by the grand delusions. Occurring with the change of ideas, there is a corresponding change of feeling. While persecuted the paranoiac is morose, sullen, silent, suspicious, treacherous and often violent; after the transformation, he becomes talkative, friendly, self-satisfied, proud and important, and may even go so far as to excuse his former imaginary persecutors.

The process by which the transformation is accomplished varies. It may result from a chain of reasoning; it may take place suddenly as a result of an hallucination, a dream, etc. Whether the result of a reasoning process or not, the secondary delusions of grandeur are always intimately logically connected with the primary delusions of persecution. Thus one person concludes, as the logical outcome of his persecutions, that he is entitled to some great privileges of honor, position or fortune which usurpers are in the enjoyment of ; and he attributes his persecution to those who occupy the place which he fancies belongs to him. Under appropriate surroundings of life and circumstances of education paranoiacs, after the transformation, become in their thought kings and princes, religious reformers, political enthusiasts, heirs to great estates, great inventors or discoverers. Love plays a prominent part in some cases. It is customary in text-books to make numerous classes of paranoia in accordance with the particular nature of the ideas expressed, but such subdivisions are of very minor importance; and besides in a single case we frequently find a combination of ideas which would require very numerous descriptive terms. Thus in all cases of paranoia, we find sexual elements; we rarely miss a distinct philanthropic motive, after the transformation; religious ideas are but exceptionally wanting; and political views of a delusional character are as common. The reason for this expression of false ideas on so many subjects lies in the fact that the whole mental personality is implicated, and therefore all thoughts and experiences are necessarily and intuitively brought into harmony with the fundamental mental tone.

In paranoia the logical and associative powers of the mind are not necessarily impaired; rather mental associations are facilitated as a result of the extra- 
ordinary intensity of consciousness characteristic of the disease. This intensity of consciousness of a direct personal kind accounts for the instantaneous mental assimilation of all ideas, no matter how incongruous or contradictory, and the forcing of them into immediate association and logical relationship with the predominating delusions. Such a phenomenon as this is only possible before much mental weakness has supervened. This automatic assimilation of incongruous ideas shows that in such a case all power of critical examination of facts has been Iost; and thus even here there is actually loss as well as distortion of mind.

Hallucinations and illusions, while not a necessary accompaniment of paranoia are rarely wanting, and when present they afford important sources for the creation and elaboration of false ideas.

It now remained to determine whether the prisoner presented a mental condition like that present in paranoia, and if so to ascertain whether it was a product of disease or voluntarily assumed to deceive.

The expansive mood previously described as presented by Arthur Duestrow, corresponds in all its features with that observed in cases of paranoia after the transformation has taken place. In this case the state of feeling was out of all harmony with actual external conditions. Was it in harmony with ideas entertained by the prisoner?

The prisoner's conversation was free and open; there was nothing in his manner to raise a suspicion of a lack of frankness; his mien was open and straightforward. Thus there was no difficulty in inducing him to be as communicative as desired. Without prompting, he went into a detailed description of ideas and experiences of a very remarkable character. He said that he had made the greatest discovery of modern times; namely, the fact of mind-transference and the ultimate possibilities of hypnotism and animal magnetism. By means of this discovery he was about to revolutionize all medical sciences, and liberate the world from crime, vice, and maliciousness. His discovery made clear to him much in his own life that had before remained inexplicable. Hypnotic influence and malicious thought-transference had been used by his enemies to control and persecute him. Thus he had been induced to drink, and injure his wife and child. After his incarceration begau, the same influences had been used to persecute and annoy him constantly, thus driving him to attempt suicide. Machines, telephones, batteries, etc., had been used in this way, by placing them in hiding in his cell and elsewhere; and he had been made to have hallucinations and delusions by the same means. This state of unmitigated persecution had continued until he had suddenly discovered the nature of the means used and the great preventive to overcome their malicious use. Since this sudden discovery he was still the object of persecution, but he obviated its effects by using his great preventive. He explained the prevention now as the natural consequence of his being a great pioneer in a new field, likening himself in this respect to Christ, Columbus and others. In this influence of hypnotism, thoughttransference and animal magnetism he found an explanation of all diseases and the way to cure all diseases. He gave the details of an elaborate and impossible theory of the relation of the spleen to the "glandular system," the blood, the body, the convolutions of the brain, and its effect to cause and cure disease by means of animal magnetism. His preventive consisted in his knowledge that possession of the "positive and negative sparks" would keep off the influence of "malicious thought-transference. He had become so accustomed to use this preventive that he could apply it effectually even in sleep, to save himself from persecutors who sought to gain control of him by exercising their influence on him while he was presumably unconscious and unable to protect himself. He asserted that all persons who in any way looked like him, had the same thoughts, the same feelings that he had; that when he was persecuted, those like him were similarly annoyed and controlled. He explained an elaborate system of colored sparks which evidenced great imaginative ingenuity. He sought to show how he could anesthetize a person at a distance by taking chloroform himself and transferring its effects by means of thought. Since his discovery he had become able to exercise the influence on any one. He could make any person do what he willed, think any thought he desired, read their thoughts, etc., etc.

The prisoner made several attempts to display his boasted powers whichwas successful only in his con. fiding imagination. These attempts were offered as demonstrations of the truth of his assertions. $\mathrm{He}$ tried to tell the hour by means of the mind of a third person in sight of a public clock; to transfer the odor of a rose from a flower-shop blocks away. $\mathrm{He}$ told of various vulgar acts to which he had forced others by his power. There was a sexual tinge in much that he said. His discovery had enabled him to read the thoughts of men the world over, and thus he was able to foretell human events. In this way he had learned of his elevation to a high position as surgeon in the army; of his relationship to certain aristocratic persons in Germany; of his election to the College of Jesuits by the Pope for services in revealing the dire designs of members of the Church of God directed against the Church of Rome. Moreover, by the use of his powers he had converted all the physicians who deemed him insane to complete recognition of his sanity. He told how, controlled by malicious thought-transference, he had been made to shoot his wife and child, but explained that the wounds were merely superficial and that they had recovered and now understood what had forced him to act so unnaturally; he had seen his wife and child (illusions) and was therefore convinced that the proceedings against him were a farce and about to be dismissed. The effort to prove him insane was but a ruse of his enemies who sought to influence the lawyers and doctors and make them believe him crazy, in the hope to get him into an asylum. He would show at his trial that he was sane and all the doctors insane. He gave a history of himself which showed that he had repeatedly had illusions and hallucinations, and while under examination he frequently gave signs of having rudimentary hallucinations. His description of hallucinatory experiences was remarkable for its originality and for its perfect correspondence with that given by insane persons of their mental phenomena.

This recital of his ideas might be much further extended, but such a narrative could add nothing to the foregoing exemplification of the general nature and character of hie intellectual operations. The prisoner's description of his life in jail and
the evidences at hand, showed that at the beginning 
of his confinement he had delusions of persecution and hallucinations; that his mood, corresponding with these, was then silent, sullen and suspicious; that suddenly, after some months, a change had come which was the inauguration of his present state of thought and feeling. The persecutory ideas had persisted but had become subsidiary to the grand delusions and logically connected with them.

No kind of contradiction or demonstration caused him to change countenance or modify his views and assertions. There was perfect harmony between his grand ideas and his expansive mood.

The manner in which the prisoner conversed and defended his impossible and absurd notions was remarkable for the readiness and rapidity with which incongruous ideas and facts were accepted, distorted and explained from his delusional standpoint. The effect of trivialities in their suggestive relation to his mental operations was at once a matter of surprise and wonder to one observing it. It could not be adequately described in words. Never was there anything thus exhibited in any way out of harmony with his predominating state of consciousmess. These were the most striking features of his mental condition taken with the constant display of his lack of critical powers.

In his ideas we find delusions of persecution, personal aggrandizements, sexual tinge, religious tendencies, philanthropic schemes, etc. He gives evidence of having had all the symptoms of the developments, course and transformation of the mental state seen in paranoia; of having at present the symptoms characteristic of that disease after the transformation has taken place. His hallucinations and illusions are characteristic in their minutest details of that malady. The instantaneous assimilation of all kinds of sense impressions and ideas, and their immediate harmonious association in consciousness, are again characteristic of certain stages of paranoia. Throughout all the system of symptoms he presents there is a perfection of harmony in their combination that leaves no doubt that he exhibits an exact portrayal of a definite type of mental disease, and that the type is paranoia. Were these symptoms feigned? Since they correspond in minutest detail in development and course with a very definite form of disease; and since they are of the greatest complexity, if feigned, their presence betokens the most profound knowledge of insanity, which could come only after years of study and observation of the insane in constant association with them. Such a knowledge could not be gained from books, much less imparted by word of mouth. If the prisoner can be shown to have spent years with the insane, and to have a mind far above the average, we may allow, for the nonce, that he feigned these symptoms. Allowing this, we should expect an absence of all the ordinary signs of feigning, as we do in this case. Allowing that the prisoner is simulating, with such a profound knowledge of insanity he would certainly choose an easier part to play. Mere delusions of persecution would serve the purpose of a simulator as well; there would be no need to go through the transformation; no need to bring in all ideas-sexual, religious, philanthropic, etc. However, in the symptoms presented by the prisoner there is an element which no person could successfully simulate, no matter if a master in knowledge of the insane mind; namely, that rapidity of reception, associa- tion and delusional interpretation of all external impressions, experiences and ideas, no matter how inharmonious or contradictory they are in fact;-a process in which there is never any flaw, never anything incompatible with the fundamental state of consciousness. Such rapidity of assimilation and association of mental impressions is seen in other forms of mental disease, but never with the logical connection and systematic creation of mental combination that characterize it when present in paranoia.

The presence of this element, associated with the other mental symptoms in this case, is positive and unmistakable evidence of disease, and as positive evidence of an absence of feigning. In any case of feigned paranoia this element would necessarily be lacking; for it is impossible for a normal mind to act in this way. The normal mind, in possession of its ordinary critical powers is, as it were, by a psychologic law, forced to exercise criticism-to compare, weigh and consider; this requires time, and is shown outwardly in hesitation, delay, uncertainty, and equivocation in the expression of judgments. The paranoiac's mind, devoid of the power of criticism, has no need to weigh or consider; as it were, the explanation of any possible event that can be presented to his mind is ready, created before the event is perceived. In other words his mind receives everything automatically, is never surprised or led away from its predestined path of activity. The reason for this peculiarity lies in the fact that the operations of the mind of the paranoiac are directed by inner cerebral conditions; whereas, in a normal mind the mental activities are constantly modified by the logic of impressions coming through the senses. This process peculiar to the mind of the paranoiac, is involuntary and incapable of voluntary imitation.

The origin, development and transformation of the prisoner's delusions are sufficient to demonstrate their relation to disease; but it might be objected that some other proofs were required to show his false ideas to be insane, rather than sane delusions; for a delusion per se is no sign of insanity. A sane delusion is a false belief that has arisen as a result of teaching, ignorance, or erroneous interpretation of experience. Such a delusion may be so tenaciously held as to resist all powers of demonstration and argument, and require a course of careful education to eradicate it. A sane delusion may at any time become an insane delusion, when appropriate conditions arise in the individual. For example, many normal persons entertain delusions concerning so-called thought-transference. Under normal conditions this error has merely an abstract value for the mind that entertains it; it bears no concrete and immediate relation to the individual. To become an insane delusion such a false belief must be brought by the mind into direct bearing upon its operations; the person must find within himself reasons which convince him of this relation -he must interpret inexplicable inner events, activities and sensations as due to the operation of the influence which he has previously believed in only in an abstract and impersonal way. The changes within himself may be normal or abnormal; the absence of critical power which enables them to be brought into immediate relation with the false belief is always due to a diseased mental condition.

Thus in the prisoner's case, his delusions are insane 
delusions because, in the abnormal absence of critical power, he brings them into direct relations with events, sensations and phenomena which are present only in his inner consciousness. These facts are sufficient to show beyond a doubt that Arthur Duestrow is insane, that he is suffering with paranoia, and that he is incapable of understanding the nature of the trial he is approaching.

I have never seen or heard of recovery in a case of genuine paranoia. I am confident that in this case an examination of the ancestral and individual history would reveal the degenerate basis of the malady. Remembering the comparatively early age (25) at which the disease reached complete development, the rapid and early completion of the transformation, and the absence of critical powers, it seems probable that dementia will supervene with comparative rapidity. By this, I mean as compared with the oncoming of dementia observed in ordinary cases of paranoia. It may be several years before the mental weakness becomes so apparent as to strike a lay observer. "Acute paranoia," so-called, is a curable disease, but to apply the word, paranoia, to any form of acute mental disease is to do violence to scientific nomenclature; there is no reason to regard this case as one of acute mental disease.

Aside from the probabilities mentioned, there are other possibilities that must be considered in this case. In any case of paranoia, remissions of short or longer duration may occur, and in such an event there is an apparent return to mental health for a time, but always ultimately the symptoms reappear, and the former delusional creations are again taken up and further elaborated. Moreover, a paranoiac may at any time simulate sanity, and that so successfully as to deceive all but the most experienced observers. The simulator of sanity reasons in this manner: "As long as I talk about my ideas, they will think me crazy and deprive me of freedom; therefore I'll conceal my ideas and accommodate myself to those who restrain me." This ruse is only too frequently successful in bringing about release from custody, and numerous paranoiacs have thus hastened from the asylum to kill some person representing an imaginary enemy. The ideas of the paranoiac are not necessarily "fixed" or unchangeable, and therefore it is to be expected that those at present entertained by the prisoner will alter more or less in time, though their general nature will not change until permanent dementia has supervened. A paranoiac may, like any man, become subject to an organic disease, such as paretic dementia; or his fundamental malady may become complicated by some acute mental disease.

Such a consideration as this, suffices to show the utter absurdity of defining a paranoiac as a person whose opinions differ from those entertained by the majority of mankind. Opinion, like a delusion, can never be a sign of insanity until it can be shown to have a foundation in disease.

1320 Union Trust Building.

1 In this report, the legal requirements restricted the writer to the condition of the prisoner subsequent to the homicide; thus an important part of the medical aspect of the case was excluded. The and hysteria in immediate collaterals. The previous history of the

\section{REMOVAL OF THE APPENDAGES AND LIGA.} TION OF THE UTERINE ARTERY TO THE U'TERO-CERVICAL JUNCTION.

\section{REPORT OF THIRTY CASES OF A NEW OPERATION.} BY BYRON ROBINSON.

\author{
CHICAGO.
}

The above operation I introduced about two years ago. The technique consists in ligating the appendages and then snipping them off. An aneurysm needle armed with a double ligature is then passed through the broad ligament at the cervico-uterine junction on the inner side of the uterine artery. The one ligature is tied along the side of the uterus including the perpendicular arteries of the uterus, the Fallopian tube, round and ovarian ligaments. The other ligature is tied on the broad ligament including the ligamentum infundibulo-pelvicum. Another method consists in ligating and removing the appendages and then simply ligating the uterine artery once or twice as it courses through the broad ligament by the side of the uterus as low down as the neck. The first method is the best, as it atrophies not only blood vessels but nerves and ganglia. We have ligated the uterine artery down to the cervicouterine junction in nearly all of the cases. No symp-

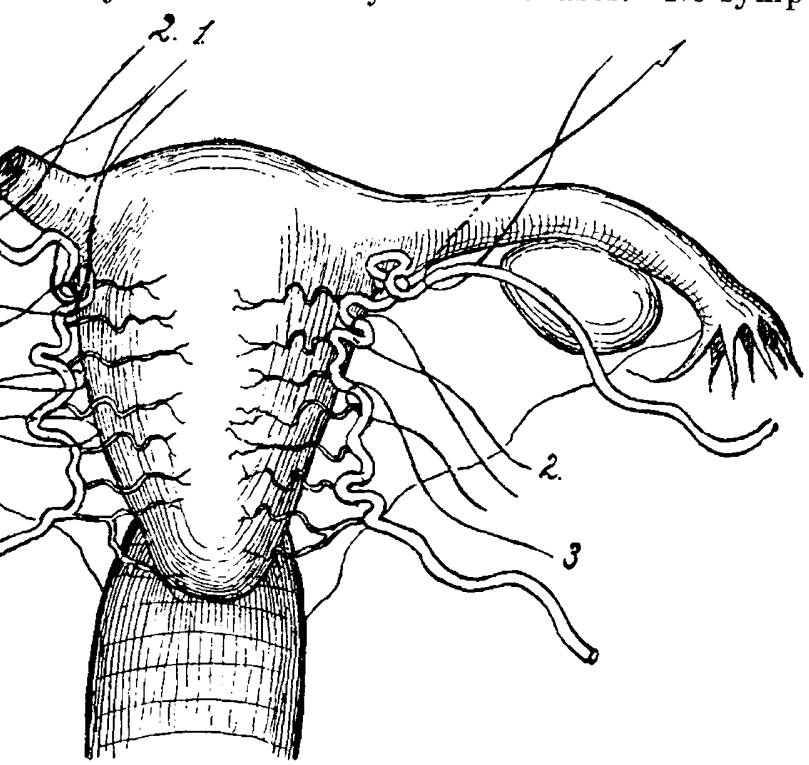

This drawing is intended to show the method of operation. The right tube and ovary have been tied by ligature 2 aud removed. I igatires 1 the lowest point at which $I$ have lignted. Ligature 5 might be considered to be withiu the danger line. The left tube and ovary have not been removed, but ligature 1 includes the tube and artery. I have ligated the uterine artery as low as the point indicated by ligature 3 on the left side. The drawing is somewhat diagramatic, but the arteries are as natural in their position aud relations as I could draw them. Lately I have only used oue double ligature to ligate the artery fully as low down as No. 5 .

toms of tissue death in the uterus have so far appeared in any of the cases. In some cases pain is severe from twenty-four to forty-eight hours, but it seems due to trauma by the ligatures on large numbers of nerves and ganglia. This pain can be quieted with $\frac{1}{16}$ gr. morphin once or twice, for the main pain is generally over in fifteen hours. This operation can be widely applied in surgical gynecology. It pro-

prisoner shows marked mental dullness. delusions of suspicion, sexual perversity and intolerance of alcohol. The double murder was premental distortion was manifested alcoholism, and the fully developed far it remains uncertain whether the crime was directy murder. Thus delusions, or the deed of an insane crime was directly the result of governable rage. 